\title{
Comparison of flexural strength and modulus of elasticity in several resinous teeth splinting materials
}

\author{
Je-In Yoo, Soo-Yeon Kim, Bayarchimeg Batbayar, Jin-Woo Kim, Se-Hee Park, Kyung-Mo Cho* \\ 'Department of Conservative Dentistry, College of Dentistry, Gangneung-Wonju National University School of Dentistry, \\ Gangneung, Republic of Korea \\ ${ }^{2}$ Mongolian National University of Medical Sciences, Ulaanbaatar, Mongolia
}

Purpose: Direct splinting material should have high flexural strength to withstand force during mastication and low modulus of elasticity to provide some movement while force applied for relief of stress. The purpose of this study was to compare flexural strength and modulus of elasticity of several resinous splinting materials. Materials and Methods: Four materials; Super-Bond C\&B, G-FIX, G-aenial Universal Flo, FiltekTM Z350 XT; were used in this study. Fifteen rectangular bar specimens of each material were prepared. Three-point bending test were performed to determine physical properties. Maximum load at fracture was recorded and flexural strength and modulus of elasticity were calculated. One-way analysis of variance (ANOVA) and Scheffe's tests at a 0.05 level of significance were conducted on all test results. Results: Statistical analysis reveals that Super-Bond C\&B had significant low mean value for flexible strength and the other three materials showed no significant difference. For modulus of elasticity, Super-Bond C\&B exhibited statistically lower modulus of elasticity. G-FIX presented intermediate result, showing statistically higher modulus of elasticity than Super-Bond C\&B but lower than G-aenial Universal Flo and FiltekTM Z350 XT. There was no significant difference on modulus of elasticity between G-aenial Universal Flo and FiltekTM Z350 XT. Conclusion: Using a G-FIX, the newly commercially available splinting material, which shows higher fracture resistance properties comparable to flowable and restorative composite resin and a relatively flexible nature might be a beneficial for stabilizing teeth mobility. (J Dent Rehabil Appl Sci 2016;32(3):169-75)

Key words: tooth mobility; splint; flexural strength; modulus of elasticity; 3 point bending test

\begin{abstract}
서론
치아의 비생리적인 동요는 치아의 외상, 치주 질환, 외 상성 교합 등에 의해 생기게 된다. 임상에서 심한 동요를 보이는 치아는 발거하게 되는 경우가 많으나 다양한 이 유들로 인해 치아의 유지가 결정된 경우 치아의 고정 술 식이 행해질 수 있다. 치아고정은 증가된 치아의 동요를 제한하고 고정하기 위하여 두 개 또는 그 이상의 치아를 연결하는 것을 의미한다. 이는 환자의 불편감을 해소하

*Correspondence to: Kyung-Mo Cho

Professor, Department of Conservative Dentistry, College of Dentistry, Gangneung-Wonju National University, 7, Jukheon-gil, Gangneung, 25457, Republic of Korea

Tel: +82-33-640-3155, Fax: +82-33-640-3103, E-mail: drbozon@gwnu.ac.kr

Received: May 31, 2016/Last Revision: July 19, 2016/Accepted: August 8, 2016
\end{abstract}

고 교합관계와 저작기능을 회복시키며, ${ }^{1}$ 저작 등의 기능 중 생기는 하중을 여러 치아와 넓은 면적으로 분산시키 고 해로운 측방하중을 수직적인 방향으로 바꿔줌으로써 동요치의 치주적 예후를 개선시키는 것을 목표로 한다. ${ }^{2}$

치아고정 재료를 포함한 구강내의 수복물은 온습한 환 경에서 장기간 저작압에 노출되며 스트레스를 받으며 이 는 재료 자체의 파절 또는 치아와 수복재의 계면의 부착 실패를 일으킨다. ${ }^{3}$ 그러므로 불리한 구강 내 환경에서 파 절되지 않고 견디기 위한 높은 강도와 법랑질에의 믿을

Copyright C 2016 The Korean Academy of Stomatognathic Function and Occlusion. (c) It is identical to Creative Commons Non-Commercial License. 
만한 접착 강도가 요구된다.

또한 치아고정 재료는 치아의 생리적인 움직임을 허용 할 수 있도록 낮은 탄성계수를 지녀야 한다. 많은 연구에 서 생리적 치아 동요를 허용하는 연성 치아고정의 이점이 보고되고 있다. ${ }^{4-7}$ 생리적인 치아의 움직임은 치아 주위 조직에 기능적인 자극을 줌으로써 치주인대 섬유의 재배 열과 치근 유착의 방지, 재혈관화 과정에 긍정적인 영향 을 준다고 알려져 있다. ${ }^{4,6,8}$ 또한 복합 레진을 포함한 취성 재료의 파절은 인장응력이 생기는 부위에서 균열이 진전 되어 일어나게 되는데, 유연한 성질을 지닌 치아고정 재 료는 그렇지 않은 것에 비하여 어느 정도의 변형에도 파 절되지 않고 더 잘 견디는 반면, 과도하게 단단한 치아고 정 재료는 중합 수축 동안 소성변형이 적게 일어나기 때 문에 응력을 완화하지 못하며 적은 응력 내구성을 지녀 점진적인 약화가 진행되기 쉽다. ${ }^{2}$

현재까지 titanium trauma splint (TTS), cap splint, 강 선 복합 레진 고정, 복합 레진 고정, 봉합 고정 등을 이용 한 다양한 치아고정 방법이 문헌에 소개되어 왔다. ${ }^{9,10}$ 여 러 방법 중, 인접치의 법랑질에 직접 재료를 접착시켜 고 정을 도모하는 레진 치아고정은 치아 삭제가 거의 필요 하지 않아 보존적이고 임상에서 적용이 간편하고 술식 시간이 빠르며 심미적으로 우수하다는 장점을 지닌다. 또한 비교적 구강위생을 방해하지 않으며 추가적인 진단 과 치료를 허용할 수 있다. 이러한 장점들로 인해 레진 치
아고정은 동요치 고정을 위한 고정 방법 중 널리 사용되 고 있는 방법 중 하나로 최근에는 레진 치아고정을 위한 전용 제품도 개발되어 출시되어 사용되고 있는 실정이다.

현재 다양한 치아고정 종류에 따른 여러 기계적 성질 또는 그 예후에 관한 많은 연구가 있으나, ${ }^{2,5,11-13}$ 레진을 이용한 동요치 고정에 사용되는 여러 재료들의 물리적 성질에 대한 연구는 매우 부족하며 특히 최근 새롭게 시 판되었거나 개발중인 제품에 관한 연구는 거의 없었다.

이에 본 연구에서는 동요치 고정에 사용될 수 있는 레 진계 치아고정 재료의 굴곡강도와 탄성계수를 평가하고 비교함으로써 임상에서의 유용성을 평가하고 임상가들 에게 있어 재료의 선택에 도움이 되고자 하였다.

\section{연구 재료 및 방법}

\section{실험 재료}

실험군으로 4종의 레진을 사용하였다. 자가 중합 레진 시멘트인 Super-Bond C\&B (Sun Medical Co Ltd, Shiga, Japan), 광중합 스플린트 재료인 G-FIX (GC Co., Tokyo, Japan), 유동성 복합 레진인 G-aenial Universal Flo A2 (GC Co.), 수복용 복합 레진인 Filtek ${ }^{\mathrm{TM}} \mathrm{Z} 350$ XT A2B (3M ESPE, St. Paul, MN, USA)를 사용하였다. 각 재료 의 구성성분은 Table 1 에 나타내었다.

Table 1. Composition of materials used in this study

\begin{tabular}{|c|c|c|}
\hline Material & Manufactures & Composition \\
\hline G-aenial Universal Flo & GC & $\begin{array}{l}\text { Matrix (31\% wt.): UDMA, Bis-MEPP, TEGDMA } \\
\text { Filler (69\% wt., 50\% vol.): } \\
\begin{aligned} \text { Silicon dioxide }(16 \mathrm{~nm}) \\
\text { strontium glass }(200 \mathrm{~nm}) \\
\text { pigment }\end{aligned}\end{array}$ \\
\hline & & Initiator: Photo initiator \\
\hline Super-Bond C\&B & Sun Medical & $\begin{array}{l}\text { Catalyst V: Tri-n-butylborane, hydrocarbon } \\
\text { Monomer: MMA, 4-META } \\
\text { Polymer: PMMA, metal oxides }\end{array}$ \\
\hline Filtek $^{\mathrm{TM}}$ Z350 XT & 3M ESPE & $\begin{array}{l}\text { Matrix: Bis-GMA, UDMA, TEGDMA, Bis-EMA } \\
\text { Filler }(78.5 \% \text { wt., } 59.5 \% \text { vol. }) \\
\text { : Aggregated zirconia/ silica cluster with primary particle size }(5-20 \mathrm{~nm}) \\
\text { : Nonagglomerated silica }(20 \mathrm{~nm})\end{array}$ \\
\hline
\end{tabular}

Data from manufacturers' websites and/or product catalogs.

Data of G-FIX was not revealed by its manufacturer.

UDMA, Urethane dimethacrylate; Bis-MEPP, 2,2-Bis(4-methacryloxypolyethoxyphenyl)propane; TEGDMA, Triethyleneglycol dimethacrylate; MMA, Methyl methacrylate; 4-META, 4-methacryloxyethyltrimellitic acid anhydride; Bis-EMA, Bisphenol-A-ethoxylated dimethacrylate; PMMA, Polymethyl methacrylate; Bis-GMA, Bisphnol-A-glycidylmethacrylate. 


\section{시편 제작}

각 재료의 굴곡강도와 탄성계수의 평가를 위해 가로 $25 \mathrm{~mm}$, 세로 $2 \mathrm{~mm}$, 높이 $2 \mathrm{~mm}$ 의 테플론 주형(Fig. 1)을 이용하여 각 실험군당 15 개씩 총 60 개의 시편이 제작되 었다. Glass mixing slab 위에 주형을 위치시킨 후 주형에 각 재료를 유입시켰다. 혼합이 필요한 Super-Bond C\&B 는 제조사의 지시대로 혼합하여 주형에 유입시켰다. 각 재료로 채워진 주형 위에 celluloid matrix를 압접한 상 태에서 압력을 주어 여분을 제거하여 균일한 두께가 되 도록 한 뒤 중합하였다. G-FIX, G-aenial Universal Flo, Filtek $^{\mathrm{TM}}$ Z350 XT 는 LED 광중합기(G-Light, GC Co.) 를 이용하여 20초씩 다른 위치에서 3회 중합하였다. 3회 의 중합 위치는 서로 중첩되게 하여 미중합되는 부위가 없도록 하였다. Super-Bond C\&B는 압력을 가한 상태로 경화될 때까지 움직이지 않고 유지하였다. 중합을 완료 한 후 시편은 주형에서 제거하여 $37^{\circ} \mathrm{C}$, 상대습도 $100 \%$ 를 유지하는 항온기(SIB-1, Seo-kwanng Sience Co., Seoul, Korea)에서 24시간 동안 보관하였다. 3점 굽힘 시 험 시행 전에 $0.01 \mathrm{~mm}$ 단위까지 측정할 수 있는 디지털 캘리퍼(CD-15CP, Mitutoyo, Kawasaki, Japan)를 이용하 여 각각의 시편의 두께와 높이를 측정하여 기록하였다.

\section{굴곡강도와 탄성계수 측정}

만능시험기(RB-306, R\&B Inc., Daejeon, Korea)를 이용하여 최대 하중 $800 \mathrm{~kg}$ 의 조건에서 분당 $1.0 \mathrm{~mm}$ 의 cross-head speed로 시편이 파절되는 시점까지 하중을 주었다. 시편에 가해진 최대 힘 $(\mathrm{N})$ 이 측정되고 기록되었 으며 굴곡강도와 탄성계수는 다음 공식에 따라 계산되었 다.

Table 2. Flexural strength of materials tested [Mean (MPa) and standard deviation]

\begin{tabular}{lc}
\hline \multicolumn{1}{c}{ Group } & $\begin{array}{c}\text { Mean }(\mathrm{MPa}) \pm \\
\text { standard deviation }\end{array}$ \\
\hline Super-Bond C\&B & $158.5 \pm 8.8^{\mathrm{a}}$ \\
G-FIX & $238.6 \pm 18.9^{\mathrm{b}}$ \\
G-aenial Universal Flo & $262.0 \pm 30.4^{\mathrm{b}}$ \\
Filtek $^{\text {TM }}$ Z350 XT & $258.2 \pm 36.0^{\mathrm{b}}$ \\
\hline
\end{tabular}

$\overline{a, b, c}$ means followed by different alphabet letters are significant difference $(P<.05)$ in each mechanical properties.

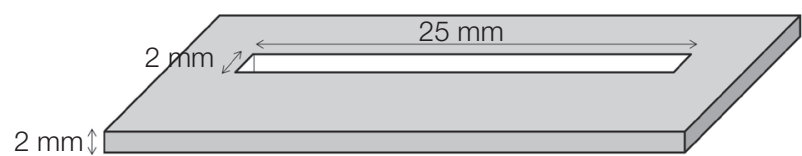

Fig. 1. Schematic drawing of the mold used for specimen fabrication.

$$
\text { 굴곡강도 } \mathrm{F}=3 \mathrm{P}_{\mathrm{f}} \mathrm{L} / 2 \mathrm{BH}^{2}(\mathrm{MPa})
$$

$\mathrm{P}_{\mathrm{f}}$ 는 시편이 파괴되는 시점의 최대 힘 $(\mathrm{N})$ 이고, $\mathrm{L}$ 은 지 지대 사이의 간격 $(10 \mathrm{~mm}), \mathrm{B}$ 와 $\mathrm{H}$ 는 3점 굽힘 시험 전에 측정된 시편의 폭과 두께( $\mathrm{mm}$ 단위)를 뜻한다.

$$
\text { 탄성계수 } \mathrm{E}=\delta_{f} / \delta_{y} \times \mathrm{L}^{3} / 4 \mathrm{BH}^{3}(\mathrm{GPa})
$$

$\delta_{f} / \delta_{y}$ 는 단위 변형률 $\left(\delta_{y}\right)$ 에 대한 응력의 변화율 $\left(\delta_{f}\right)$ 이고 $\mathrm{L}$ 은 지지대 사이의 간격 $(10 \mathrm{~mm}), \mathrm{B}$ 와 $\mathrm{H}$ 는 3점 굽힘 시 험 전에 측정된 시편의 폭과 두께( $\mathrm{mm}$ 단위)를 뜻한다.

\section{통계 분석}

SPSS Ver 21.0 (SPSS Inc., Chicago, USA)를 사용하 여 측정된 굴곡강도와 탄성계수에 대한 정규분포 검정을 시행한 후 One-way ANOVA test로 분석하였다. 이 후 95\% 유의수준에서 Scheffe's test로 사후 검정하였다.

\section{결과}

각 실험재료의 굴곡강도와 탄성계수의 평균과 표준편 차는 각각 Table 2 , 3에 나타내었다. 이를 바탕으로 One-

Table 3. Modulus of elasticity of materials tested [Mean

\begin{tabular}{|c|c|}
\hline Group & $\begin{array}{c}\text { Mean }(\mathrm{MPa}) \pm \\
\text { standard deviation }\end{array}$ \\
\hline Super-Bond C\&B & $16.2 \pm 4.5^{\mathrm{a}}$ \\
\hline G-FIX & $24.9 \pm 2.5^{\mathrm{b}}$ \\
\hline G-aenial Universal Flo & $60.4 \pm 5.5^{c}$ \\
\hline Filtek $^{\mathrm{TM}}$ Z350 XT & $64.0 \pm 5.1^{\mathrm{c}}$ \\
\hline
\end{tabular}
(GPa) and standard deviation] 
Table 4. Result of One-way ANOVA test on flexural strength

\begin{tabular}{ccrccc}
\hline & Sum of squares & df & Mean square & F & Sig. \\
\hline Intergroup & 105115.15 & 3 & 35038.38 & 52.778 & \\
Intragroup & 37177.31 & 56 & 663.88 & & \\
Sum & 142292.46 & 59 & & \\
\hline
\end{tabular}

df, degree of freedom; Sig., significance.

Table 5. Result of One-way ANOVA test on modulus of elasticity

\begin{tabular}{ccrrrr}
\hline & Sum of squares & df & Mean square & F & Sig. \\
\hline Intergroup & 26639.52 & 3 & 8879.84 & 429.66 & \\
Intragroup & 1157.37 & 56 & 20.67 & & \\
Sum & 27796.89 & 59 & & & \\
\hline
\end{tabular}

df, degree of freedom; Sig., significance.

way ANOVA test와 Scheffe's test를 시행하여 그룹 내, 그룹 간의 통계적 유의성을 살펴본 결과를 Table 4, 5에 나타내었다.

본 연구의 결과 굴곡강도에서는 Super-Bond C\&B 는 다른 재료들과 비교 시 유의하게 낮은 평균 굴곡강 도를 보였다 $(P<0.05)$. 이와 비교하여 G-FIX, G-aenial Universal Flo, Filtek ${ }^{\mathrm{TM}} \mathrm{Z} 350$ XT는 비슷하게 높은 굴곡 강도를 나타내었으며 이들 사이에 통계적으로 유의한 차 이는 없었다 $(P>0.05)$.

탄성계수의 경우 Super-Bond C\&B가 가장 낮은 값을 보였고 $(P<0.05)$ G-FIX는 Super-Bond C\&B보다는 높 지만 G-aenial Universal Flo와 Filtek ${ }^{\mathrm{TM}}$ Z350 XT보다 는 낮은 탄성계수를 보였으며 G-aenial Universal Flo와 Filtek $^{\mathrm{TM}} \mathrm{Z} 350 \mathrm{XT}$ 는 유의하게 높은 탄성계수를 보였다. G-aenial Universal Flo와 Filtek ${ }^{\mathrm{TM}}$ Z350 XT는 통계적으 로 유의한 차이는 없었다 $(P>0.05)$.

\section{고찰}

본 실험에서 사용된 Super-Bond C\&B는 4-META/ $\mathrm{MMA}-\mathrm{TBB}$ 를 포함하는 자가 중합형 레진 시멘트로 다 른 재료들에 비해 유의하게 낮은 굴곡강도와 탄성계수 를 보였다. 굴곡강도와 탄성계수와 같은 레진의 기계적 성질은 사용된 모노머의 종류와 양, 무기질 필러의 종류 와 입자 크기, 커플링제의 종류 및 개시제의 양 등에 의해
영향을 받는다. ${ }^{14}$ 레진 기질에 포함되어 있는 필러 입자들 은 기질 그 자체보다 훨씬 강한 기계적 성질을 나타내기 때문에 무기질 필러의 함량이 높을수록 높은 굴곡강도와 탄성계수를 갖게 된다. ${ }^{14,15}$ 이는 무기질 필러를 포함하지 않는 Super-Bond C\&B가 다른 복합 레진들에 비해 현저 히 낮은 기계적 성질을 보이는 이유에 대한 설명 중 하나 가 될 수 있을 것이다.

또한 Super-Bond C\&B는 사용 전 액체와 분말을 혼합 하는 과정을 거치게 되며 혼합 과정 중 불가피하게 공기 가 유입되어 구조를 약하게 하는 기포를 생성하게 되며 산소의 유입은 중합과정을 방해한다. ${ }^{16}$ 이는 시편 간의 오차를 야기하며 낮은 굴곡강도와 탄성계수에 영향을 미 쳤을 가능성이 있다.

기존에 치아고정 재료로 많이 사용되던 Super-Bond $\mathrm{C} \& \mathrm{~B}$ 는 앞에서 설명한 것과 같이 낮은 물성 및 조작의 차 이가 물성에 큰 영향을 미친다는 단점 이외에도 광중합 복합 레진과 비교시 작업시간을 조절할 수 없고 경화시 간이 길어 임상에서 사용하기에 불리한 점이 있다.

실험에 사용된 3 종류의 광중합 복합 레진(G-FIX, G-aenial Universal Flo, Filtek ${ }^{\text {TM }}$ Z350 XT)은 서로 비슷 하게 높은 굴곡강도를 보였으며, G-FIX는 Super-Bond $\mathrm{C} \& \mathrm{~B}$ 보다는 높으나 다른 광중합 복합 레진들보다는 유 의하게 낮은 탄성계수를 보였다. 제조사에서 제시하는 구성성분과 함량을 확인해 보았을 때 G-aenial Universal Flo와 Filtek ${ }^{\mathrm{TM}} \mathrm{Z} 350$ XT는 많은 양의 필러를 함유할 
수 있고 이는 뛰어난 기계적 성질을 보이는 이유로 생 각해 볼 수 있다. 두 복합 레진의 필러 함유량을 비교시 G-aenial Universal Flo는 69\% wt., 50\% vol., Filtek ${ }^{\text {TM }}$ $\mathrm{Z} 350 \mathrm{XT}$ 는 $78.5 \%$ wt., $59.5 \% \mathrm{vol}$ 의 필러를 함유하고 있었으며 필러 함량이 많은Filtek ${ }^{\mathrm{TM}} \mathrm{Z} 350$ XT에서 높은 굴곡강도와 탄성계수를 보일 것을 기대하였으나 이번 연 구에서는 유의한 차이를 확인하지 못하였다. 또한 두 재 료는 공통으로 포함된 UDMA, TEGDMA에 더하여 G-aenial Universal Flo는 Bis-MEPP를, Filtek ${ }^{\mathrm{TM}}$ Z350 XT는 Bis-GMA와 Bis-EMA를 포함한다. 모노머는 광 중합 레진의 물리적 성질에 영향을 미치는 요인 중 하나 로 여겨지며 기존 연구에서 건조한 환경에서 Bis-MEPP 를 포함한 레진은 Bis-GMA를 포함한 레진 보다 높은 굴 곡강도와 낮은 탄성계수를 보인다고 보고된 바 있으나 ${ }^{17}$ 역시 이번 연구에서는 확인하지 못하였다. 이는 모노머와 필러 및 커플링제의 종류, 각 구성 성분의 함량 등에 의한 영향이 복합적으로 작용하여 실험 결과에 나타났기 때문 으로 생각된다.

G-FIX의 경우 높은 굴곡강도와 상대적으로 낮은 탄 성계수를 보이며 이를 설명하기 위하여 구성성분과 함량 을 알아보려 하였으나 제조사에서 자세한 정보를 제공하 지 않고 이에 대한 연구도 아직 미미하기 때문에 설명하 기에 어려움이 있다. 제조사에서 설명하는 바에 따르면 G-FIX는 새로 개발한 고인성 모노머(elastic crosslinking monomer)를 채택하여 사용함으로써 동요치 고정에 적 합한 유연성과 점인성을 부여하였다고 했으며 이를 설명 하기 위해서는 추가적인 정보와 연구가 필요할 것이다.

굽힘 시험에 사용되는 시편의 제작은 국제 표준 규격 (ISO) 4049에 의한 방법이 널리 사용되고 있다. ${ }^{18-20}$ 본 연 구에서도 이에 따라 $25 \times 2 \times 2 \mathrm{~mm}$ 의 시편이 제작되었 으며 $2 \mathrm{~mm}$ 의 시편 두께는 광중합 시에 균일하고 효과적 인 중합이 가능한 두께이다. ${ }^{21}$ 그러나 굽힘 시험에 사용된 시편의 길이 $(25 \mathrm{~mm})$ 는 구강 내 수복물에 사용되는 직경 과 비교시에 차이가 크며 이러한 시편의 길이는 굽힘 성 질에 영향을 미칠 수 있으므로 임상적으로 보다 현실적 인 길이의 시편을 이용한 굽힘 시험이 필요하다고 이전의 연구에서 언급된 바 있다. ${ }^{22}$ 본 연구에서도 치아고정 재료 가 치간의 협소한 공간에 적용됨을 고려했을 때 구강 내 의 임상적인 상황과 실험 환경의 편차가 있을 것이라고 유추할 수 있다.

또한 시편의 길이 $(25 \mathrm{~mm})$ 는 3 가지 광중합 복합 레진 의 중합에 사용된 광 조사기의 출력창의 직경보다 길기
때문에 미중합되는 부위가 없도록 다른 위치에서 3 회 광 중합 하였으며 이 과정에서 중합이 중첩된 부위가 생긴 다. 이러한 중첩된 중합이 복합 레진의 굽힘 성질에 미치 는 영향에 대해 언급한 기존 연구에 의하면 중첩된 중합 이 이루어진 부위는 인접한 다른 부위에 비해 증가된 빛 에너지의 밀도를 받으며 이는 시편의 비균일한 중합을 야기한다고 하였으며, ${ }^{22}$ 이는 실험 결과의 오차로 작용할 가능성이 있다.

동요치 고정을 목적으로 개발된 G-FIX는 유동성 복합 레진과 수복용 복합 레진과 비등한 굴곡강도를 보이면 서도 상대적으로 낮은 탄성계수를 보여 이러한 측면에서 동요치 고정에 유리한 재료라고 사료된다. 그러나 어느 정도의 탄성 계수를 가지는 치아고정 재료가 임상적으로 유리할 것인지에 대한 추가적인 연구가 필요할 것이다.

또한 이번 연구에서 조사한 굴곡강도와 탄성계수는 치 아고정 재료의 선택 시 고려되는 성질 중 일부분일 뿐이 며, 성공적인 치아고정을 위해서는 이 외에도 법랑질과의 접착 강도, 중합 수축, 용해도, 생체 적합성, 조작성, 심미 성 등 다양한 요소가 복합적으로 고려되어야만 한다.

\section{결론}

동요치의 고정에 사용될 수 있는 여러 레진계 치아고 정 재료의 굴곡강도와 탄성계수를 3점 굽힘 시험을 통 해 알아보았으며 G-FIX는 동요치 고정을 위해 기존에 많이 이용되던 Super-Bond C\&B 보다 크고 G-aenial Universal Flo 및 Filtek ${ }^{\mathrm{TM}}$ Z350 XT와 유사한 굴곡강도 를 가져 잘 파절되지 않으면서도 상대적으로 유연한 성 질을 보여 동요치 고정에 유리할 것으로 생각된다.

\section{Acknowledgements}

이 논문은 2015년도 강릉원주대학교 학술연구조성비 지원에 의하여 수행되었다.

\section{ORCID}

Je-In Yoo http://orcid.org/0000-0001-8378-2439

Soo-Yeon Kim http://orcid.org/0000-0001-7437-6877

Bayarchimeg Batbayar http://orcid.org/0000-00018826-7989

Jin-Woo Kim http://orcid.org/0000-0002-0004-0710 
Se-Hee Park http://orcid.org/0000-0002-4052-4082

Kyung-Mo Cho http://orcid.org/0000-0003-3464-9425

\section{References}

1. Bernal G, Carvajal JC, Muñoz-Viveros CA. A review of the clinical management of mobile teeth. J Contemp Dent Pract 2002;3:10-22.

2. Mazzoleni S, Meschia G, Cortesi R, Bressan E, Tomasi C, Ferro R, Stellini E. In vitro comparison of the flexibility of different splint systems used in dental traumatology. Dent Traumatol 2010;26:30-6.

3. Wood M, Kern M, Thompson VP, Romberg E. Ten-year clinical and microscopic evaluation of resin-bonded restorations. Quintessence Int 1996;27: 803-7.

4. Burcak Cengiz S, Stephan Atac A, Cehreli ZC. Biomechanical effects of splint types on traumatized tooth: a photoelastic stress analysis. Dent Traumatol 2006;22:133-8.

5. Andreasen JO, Andreasen FM, Mejàre I, Cvek M. Healing of 400 intra-alveolar root fractures. 2. Effect of treatment factors such as treatment delay, repositioning, splinting type and period and antibiotics. Dent Traumatol 2004;20:203-11.

6. Andreasen JO, Andreasen FM, Andersson L. Textbook and color atlas of traumatic injuries to the teeth. 4th ed. Oxford; Blackwell Munksgaard; 2007. p. 842-9.

7. von Arx T. Splinting of traumatized teeth with focus on adhesive techniques. J Calif Dent Assoc 2005;33:409-14.

8. Bauss O, Schwestka-Polly R, Schilke R, Kiliaridis S. Effect of different splinting methods and fixation periods on root development of autotransplanted immature third molars. J Oral Maxillofac Surg 2005;63:304-10.

9. von Arx T, Filippi A, Lussi A. Comparison of a new dental trauma splint device (TTS) with three commonly used splinting techniques. Dent Traumatol 2001;17:266-74.

10. Filippi A, von Arx T, Lussi A. Comfort and discomfort of dental trauma splints - a comparison of a new device (TTS) with three commonly used splinting techniques. Dent Traumatol 2002;18:275-
80.

11. Prévost J, Granjon Y. An in vitro study of the passivity of splints in dental trauma. J Dent 1998;26: $39-45$.

12. Prévost J, Nivoit M, Granjon Y. Management of dental trauma: development of a $2 \mathrm{D}$ data acquisition system to evaluate passivity of dental splints. Med Biol Eng Comput 1997;35:409-14.

13. Menendez ME, Thornton E, Kent S, Kalajian T, Ring D. A prospective randomized clinical trial of prescription of full-time versus as-desired splint wear for de Quervain tendinopathy. Int Orthop 2015;39:1563-9.

14. Monteiro GQ, Montes MA. Evaluation of linear polymerization shrinkage, flexural strength and modulus of elasticity of dental composites. Mater Res 2010;13:51-5.

15. Hofmann N, Papsthart G, Hugo B, Klaiber B. Comparison of photo-activation versus chemical or dual-curing of resin-based luting cements regarding flexural strength, modulus and surface hardness. J Oral Rehabil 2001;28:1022-8.

16. Anusavice KJ, Phillips RW. Phillips' science of dental materials. 11th ed. St. Louis; Saunders; 2003. p. 410.

17. Kawaguchi M, Fukushima T, Horibe T. Effect of monomer structure on the mechanical properties of light-cured unfilled resins. Dent Mater J 1988;7: 174-81.

18. Chang M, Dennison J, Yaman P. Physical property evaluation of four composite materials. Oper Dent 2013;38:E144-53.

19. Azillah MA, Anstice HM, Pearson GJ. Long-term flexural strength of three direct aesthetic restorative materials. J Dent 1998;26:177-82.

20. Attar N, Tam LE, McComb D. Flow, strength, stiffness and radiopacity of flowable resin composites. J Can Dent Assoc 2003;69:516-21.

21. Yap AU. Effectiveness of polymerization in composite restoratives claiming bulk placement: impact of cavity depth and exposure time. Oper Dent 2000;25:113-20.

22. Yap AU, Teoh SH. Comparison of flexural properties of composite restoratives using the ISO and mini-flexural tests. J Oral Rehabil 2003;30:171-7. 


\section{여러 레진계 치아고정 재료의 굴곡강도 및 탄성계수 비교}

\section{유제인', 김수연 ${ }^{1}$, Batbayar Bayarchimeg ${ }^{2}$, 김진우 ${ }^{1}$, 박세희', 조경모 ${ }^{1 *}$}

${ }^{1}$ 강릉원주대학교 치과대학 치과보존학교실

${ }^{2}$ 몽골 국립의과학대학교 치과대학

목적: 본 연구의 목적은 수종의 레진계 치아고정 재료의 굴곡강도와 탄성계수를 비교 분석하는 것이다.

연구 재료 및 방법: 레진계 치아고정 재료로 Super-Bond C\&B (SB), G-FIX (GF), G-aenial Universal Flo (GU), Filtek $\mathrm{Z} 350 \mathrm{XT}$ (FZ)를 이용하여 각 군당 15개씩 총 60 개의 시편을 제작하였다. 3점 굽힘 시험으로 측정된 값에 따라 굴곡강도 와 탄성계수를 계산하였다. 실험값은 One-way ANOVA test로 분석하고, Scheffe's test로 사후 검정하였다.

결과: 본 연구의 결과 $\mathrm{SB}$ 는 다른 재료들과 비교 시 가장 낮은 굴곡강도를 보였으며 GF, GU, FZ는 비슷하게 높은 굴곡 강도를 보였다. 탄성계수의 경우 SB가 가장 낮은 값을 보였고 GF는 SB보다는 높지만 GU와 FZ보다는 낮은 탄성계수 를 보였으며 GU와 FZ는 유의하게 높은 탄성계수를 보였다.

결론: 동요치 고정을 목적으로 새로 개발된 GU (G-FIX)는 유동성 복합 레진과 수복용 복합 레진과 같이 높은 강도를 보이며 잘 파절되지 않으면서도 상대적으로 유연한 성질을 보여 동요치 고정에 유리할 것으로 사료된다.

(구강회복응용과학지 2016;32(3):169-75)

주요어: 치아 동요; 고정; 굴곡강도; 탄성계수; 3점 굽힘 시험

*교신저자: 조경모

(25457) 강원도 강릉시 죽헌길 7 강릉원주대학교 치과대학 치과보존학교실

Tel: 033-640-3155 | Fax: 033-640-3103 | E-mail: drbozon@gwnu. ac. kr

접수일: 2016년 5월 31일 | 수정일: 2016년 7월 19일 | 채택일: 2016년 8월 8일 